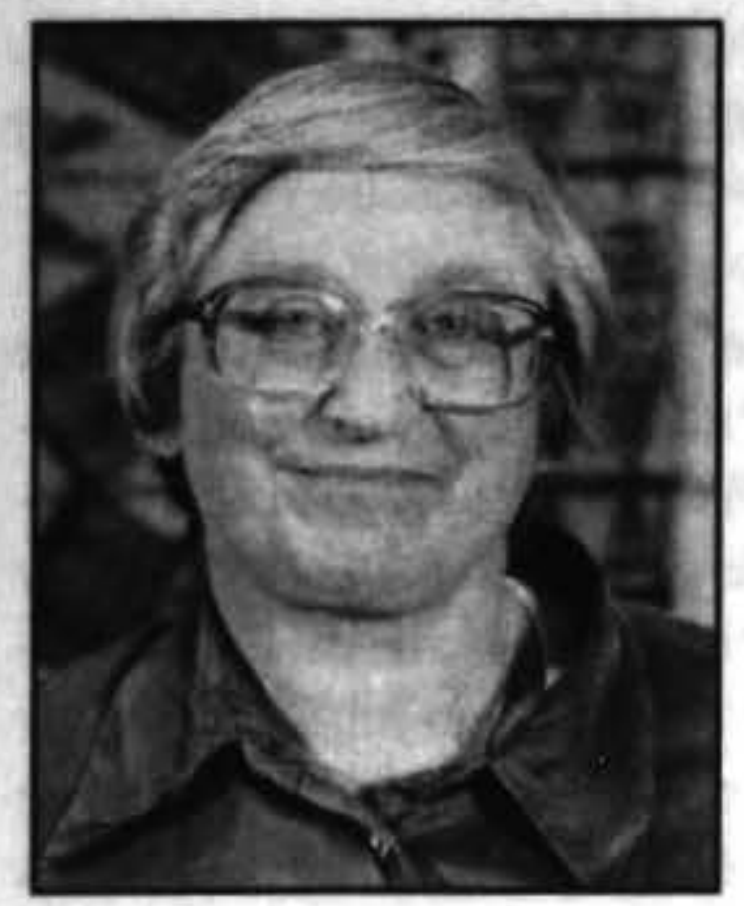

\title{
THE ARMED FORCES AND THE \\ POLICE: BARRIERS TO GENDER \\ EQUITY/ INTEGRATION \\ - THE LAST BASTION?
}

\author{
Prue Hyman
}

Women's Studies

Victoria University of Wellington

\begin{abstract}
The Armed Forces and the Police are heavily male workplaces worldwide, although each is increasing its female representation in New Zealand and most western countries. Their historic roles and previous exclusion of women give rise to strongly male cultures and greater difficulties than most workplaces in combining work and family and reaching top positions. This paper discusses these barriers to gender equity and integration and the extent to which they are reducing, using mainly the author's recent interview/focus group study of the NZCIB and also referring to Clare Burton's study of the New Zealand Defence Forces. It briefly considers the prospects for change and the dilemmas for feminists working for gender equity in these sectors.
\end{abstract}

Keywords: Gender equity, policelarmed forces

New Zealand is again making a name for itself overseas for gender equity, due to the number of women in high places. However, beneath and away from these mainly public sector top positions, barriers to gender equity and integration continue to prevent women from realising their full potential in paid work in New Zealand, as elsewhere. Overseas studies of enterprises in a wide range of occupations and industries show the persistence of barriers. Analysis of local government, banking, and nursing in the U.K., for example, found considerable advances for women compared with the days of linear career structures for men only, and yet structural gender segregation was still observed, with organisational processes and continuing to generate gendered career paths. Women in all three sectors saw themselves as having to choose between children and high career ambitions (Halford, Savage and Wilz, 1997).

Heavily male workplaces give rise to extra problems for most women, standing out in a male dominated culture. This has been documented both with respect to female apprentices in blue collar trades and in the armed forces/ police. These latter areas involve structured hierarchies, chains of command and expectations of instant obedience, exposure to physical danger, high stress, public visibility, and long and uncertain hours thrown together with colleagues. The cultures of both organisations, involving camaraderie and practices built up over a long period related to these features, are inevitably slow to change.

A recent book on British policing similarly argues in a section headed 'Male-dominated workplaces: a danger zone for women' that the resulting inevitable and beneficial male bonding has a downside in that it 'excludes anyone not accepted as part of the in-group', with it 'easier to treat women and ethnic minority colleagues as outsiders, reinforcing the group culture rather than shift the group norms so as to accommodate the newcomers' (Gregory and Lees, 1999, p 50). The authors state that it is still the prevalent view in the force that "policework is essentially masculine, apart from a few low status areas of work where women's 'natural' caring and listening skills may be usefully harnessed' ( $\mathrm{p} 26)$.

This paper examines the nature and extent of barriers facing women officers in the New Zealand Police in general, and Criminal Investigation Branch (CIB) in particular, based on my recent report on research commissioned by the National Crime Manager. This involved interviews with senior managers and other key informants and focus groups (conducted jointly with Constable Vivienne Scott) covering female and male officers, mainly in CIB, but also some from elsewhere in police and others who had disengaged. Details of methodology, including the semi-structured focus group schedule, can be found in Hyman (2000). All the quotes in this paper from individual police personnel are also contained in that report. Some references and comparisons are made with the Defence Forces, for which a more comprehensive study of gender integration had been conducted two years earlier by the late Clare Burton (Burton, 1998). 


\section{Police Gender Statistics}

The representation of women in the Police has increased steadily, then rapidly, from $2.37 \%$ in $1970,4.23 \%$ in 1980 , and $6.89 \%$ in 1990 , to $15.28 \%$ in 2000 , just above the $14 \%$ in Britain, but the proportion is only about $11 \%$ in CIB. The average age and years of service of women leaving the force between 1990 and 1997 were each seven years lower than for men, so retention is a problem, with few women reaching high rank. The most senior officer currently is at Superintendent level, with the top 27 officers all male, and only $3 \%$ of Inspectors, $2.4 \%$ of Senior Sergeants, and $5 \%$ of Sergeants being female. It is harder in the police force than in most workplaces to combine work and family responsibilities. Part time work, known as the Flexible Employment Option (FEO) is available, but only 83 sworn police officers ( 79 women, 4 men), $1.2 \%$ of the total or $7.2 \%$ of the female staff, are currently using it, a small fraction of the proportion in the labour force overall. About $20 \%$ of the New Zealand Defence Force personnel are women.

\section{Gender Barriers in the CIB/Police - None, Barriers to Men or Barriers to Women?}

A few women officers consider that there are now no barriers to their recruitment or advancement within Police/ $\mathrm{CIB}$, and most consider that the problem of a heavily male culture is slowly improving as women become more accepted and are treated more as individuals and on merit. A number of male officers, mainly at lower levels, believe that there are in fact reverse barriers, with the management commitment to advancement of women and ethnic minorities starting to disadvantage white male staff.

I think the hardest person to try and get in the Police at the moment would be a white middle class male from a rural South Island town. You'd have no show, which is disappointing because that's for many years been the back bone of the New Zealand Police, but now you have to be a half Tongan, half Maorifemale. They'd give you an air ticket when you walked into the recruiting office. You see it all the time. You go to College and it's just unbelievable. You' re walking round and they' re taking all shapes and sizes.

If anything, I'd say females have got a better deal than we have. The white male, like all of us here today, we' re so disadvantaged today it's not funny. (Male Detectivel Constables)

Reverse discrimination is certainly not policy and needs to be avoided as undesirable and to minimise resentment and misunderstanding of otherwise good EEO/gender integration policies. However, the overall statistics and experiences of many women officers discussed below speaks for themselves in terms of where the bulk of gender discrimination occurs, despite the male backlash demonstrated above.

A large majority of women officers in the study believe that their status as a small minority both in itself constitutes and also leads to a considerable degree of disadvantage, with the lack of role models and mentors. Many women officers stressed the need to 'fit' and establish credibility within CIB, and felt that this was made harder for women, with the need to perform better than one's male counterparts. Individual relationships with male colleagues were generally good, but male group behaviour was often still a problem. A lack of equal opportunity to perform all roles within CIB was another major issue, with a tendency still to assign women to interview female complainants, as against offenders, for example, and to protect them in a way that was not considered appropriate. The two major groupings of perceived barriers to women in the police were these issues, which can broadly be termed police culture, and those related to work and family.

\section{Barriers to Women in CIB/Police - Police Culture}

Examining some of these points in more detail, some male Detective/Constables in the police believe that women should simply fit into the existing culture - otherwise one has 'minority rule'.

Well, some women are sensitive and you can't say certain things around them or you can't act in certain ways. You can't be yourself.

If a woman does come in - the old hairy armpit brigade - and wants change, it doesn't go down well: it gets everybody's backs up. It just makes more of a problem.

I think the biggest problems for females in the CIB is that some are too sensitive. They might find it difficult on some squads.

It's minority rule in some of these squads, with the minority affecting the behaviour of the majority. To have women come in and have minority rule, some squads don't take kindly to it.

The need to 'fit', establishing and maintaining credibility, was a recurring theme, clearly of huge importance to a police/CIB career, and perceived by women as harder for them.

You might make a mistake. They will ridicule you for it and yet if a guy makes a mistake he is not so easily identifiable and that is where the bias comes in. You stand out. 
So it comes down to who you are. Because you are visible as a woman the scrutiny is way more. We all know we are scrutinised way more, we stand out, our work is critiqued.

I still harp back a little bit to 'one female stepped out of line, all females have stepped out of line'. That's not to the same extent as it used to be. (Female Sergeants)

Closely allied to the notion that mistakes by women will be noticed more is the belief that women have to be better achievers than their male colleagues.

I can see the hassles women in the police have had. They've had to be not as good as, but probably better. They had to be of a higher standard. Used to be that the guys could slack around and put in work that was okay but not exceptional. If a woman did that in CIB back then they'd be called up or somebody would be saying 'what a slack bitch', whereas the guys would be able to get away with it. (Detective Inspector)

I think there are two things, one that it is perceived by themselves that they have to perform that way - to be better than male police officers, and two that some policemen are arrogant enough to make them feel that way. (Male Sergeant)

There was a determination by women to perform well both from pride in the job and oneself, but also because one already stood out as a woman.

Everywhere you go in Police as a woman you have to prove yourself. We have to prove we are not just as good, but better than our male colleagues and most of us strive to be better because that comes back to acceptance and comes back to being part of a team. (Sergeant Catherine McEvedy)

It is a virtually unanimous view among women, as well as men, that women should be appointed, evaluated and promoted strictly on merit, with no preferential treatment (nor detrimental) on gender grounds. Women officers believe that they fully earn everything they get and are outraged by any suggestion of gender preference.

I've worked very hard to get what I've got, and if anybody turned around and said 'You' re where you are because you' re a female', I would just lose the plot. (Female Sergeant)
On the treatment of individual women by individual men, some women have had nothing but good experiences, others have had one bad supervisor or peer, while some talk of substantial numbers of bad encounters. It is common for female officers to find individual men easy to deal with but a large group less so, with them at times displaying offensive or insensitive behaviour, in the form of anti woman jokes, mild levels of harassment or other pack behaviour.

It's male culture and we're always considered fortunate to be there, and that's how I felt a lot of the time.

It only is like that because of the pack - they all egg each other on. Split them up and they're not like that at all.

(Female Detective/Constables)

It is clear that a single isolated woman usually has a harder time than when two or more women are present on a squad or in an office.

Although I'd gone into a good office, it was really good with two of us. It was unbelievable the change. I think it makes a huge difference.

When I was in CIB there were two of us there and now there's just women everywhere, it's great because there are more of them. The guys tend to be more accepting and work much better with them because they're so used to having women detectives.

(Female Detective/Constables)

Gender harassment, with varying degrees of seriousness, may well be more of a problem than clearly illegal sexual harassment, due to its greater prevalence and a lack of agreement over what is unacceptable. Fairly trivial behaviours such as jokes, sexual teasing, and displaying sexual material, which many men may not view as offensive, can accumulate for women on a daily or weekly basis, becoming common and irritating occurrences. Some are more affected by it than others, as illustrated by this group of female Detective/Constables:

I don't take the flippant remarks personally because I've worked with guys in this job and you know the sense of humour so I am not insulted.

When they get in with other men that have been in the job for a while they soon adopt the same attitudes.

On their own they can be really nice chaps but in a group situation it is quite intimidating especially socially. 
It does wear you down a bit. I went through a bad period with a male supervisor who basically didn't like me because I was female. The amount that that particular individual has got away with over the years is just appalling. It's pure sexist behaviour.

\section{Sometimes I don't think you can blame in-} dividuals, I think you just blame the whole Police system.

There are considerable difficulties involved in making complaints, however justified, whether superiors or peers are involved. Many women officers prefer to deal with matters themselves, by ignoring them or confronting the perpetrators about the behaviour, with a concern one will be labelled a trouble maker through making a complaint, and career and relationships with other staff will suffer, whatever the outcome. It was a common view that many people at all ranks know who the problem officers are, but that supervisors turn a blind eye, despite performance appraisal systems, sometimes 'exporting' the problem to another district, with it being extremely difficult and rare to be dismissed

Similar scepticism was expressed about the realities of Equal Employment Opportunity policies in the Police. Good policies and statements exist without an adequate range of human resource management practices, training, monitoring, and positive and negative incentives to achieve results.

\section{I think that we give a lot of lip service and tokenism to our commitment to EEO in the police. I think that we need training not just on women's issues of course but all sorts of EEO issues. (Superintendent Sandra Manderson)}

I just wish the police would honour their EEO policy. I am EEO Liaison Officer and $I$ absolutely refuse to go to training days and give the EEO speech because I know deep in my heart, the police don't honour EEO policies. (Female Detective/Constable)

As with EEO, the full range of modern gender neutral human resource policies need not simply to be in place on paper, but actively implemented. Many women believed that recruitment to CIB was too often a matter of shoulder tapping, while in some regions informal limits on female recruitment still operated. Similarly on human resource management in the Defence Forces, Burton concluded that

Although, on the whole, senior male officers recognise the possibility of bias intruding into some of the career management mechanisms, this recognition is by no means as widespread as the sentiments regarding gender bias expressed by women. Research shows that the more subjectivity and arbitrariness there are in HRM policies and practices, the more a traditional bias prevails, $a$ bias for what has come before' (Burton, 1998, p 81)

\section{Barriers to Women in CIB/Police - Work and Family}

On combining work and family, some believed that Police/CIB organisation could not bend any further than it had to accommodate the issues. More men emphasised individual choice - if one can't organise child care and family responsibilities around work schedules as currently organised, one simply can't do the job. By contrast, more women stressed structural issues and believed that organisational flexibility was necessary to allow combining home and family. However, as things are, many do not want to stand out or be seen as not pulling their weight, a concern constantly reiterated in this research.

Similarly in the Defence Forces Study, Burton found that men and women tended to see the obstacles to gender integration differently.

Men are more likely than women to focus
on women's personal attributes, job choices
and family responsibilities as reasons for
their under-representation in the miltary,
including at senior levels. Women's experi-
ences suggest to them that the fundamental
issue that needs to be addressed is the per-
vasiveness of the masculinity of the military
culture (p xiii).

The difference in emphasis between male and female police officers is demonstrated in the following exchange in our only mixed gender focus group.

Talking to one staff member recently who is away, her position was that if she could just have a five year break from the police and then come back, she would be in boots and all. She is a really competent detective but she has got a family problem she has to go and sort out. People don't want to resign because they have been in the job 14 years. They want to come back in 5 years time when the kids are off at school and put in the 8 hours. (Male)

Some bosses just won't even entertain the idea of people applying for FEO and others are open to it. (Female)

I don't think the CIB should pick up people
who have got extra baggage whether they
be males or females. If somebody has prob- 
lems with kids, why should we have them if they are going to have to deal with baby sitting issues and can't go to callouts and can't be called out for a week to deal with homicides and such like? (Male)

Is it not better though to retain the skills if you can manage the business around it? (Female)

\section{But it doesn't get managed. (Male)}

What I am saying is that if you have got a pool of people coming into CIB and two are both as good as each other, surely the one who has got the baggage, for want of a better word, is the one that should be overlooked. Not selected because that person is a female because we are trying to get numbers up in the CIB. (Male)

FEO has been around for a number of years now, but because of the scenario you outlined, many don't even ever think about FEO. Four years down the track when she wants to come back full time, you still have got a qualified Detective who has done the training, done the hard graft and is coming back to work quite happily full time. It's the marketing aspect of it. Supervisors don't do it. (Female)

Police management expressed a desire to retain the skills of experienced women CIB officers, but whether preparedness to change matches good intentions is untested. Uncertain, unsocial, and long hours, callouts and investigations away from home are all Police, and particularly CIB practices which make family care commitments a real problem. The possible conflicts with the needs of operational policing, particularly in CIB, is a major dilemma, with the Police Association among those torn on the issue.

\begin{abstract}
I feel there is not much room to carry people who can't contribute fully to the intensity of the investigation. That is the issue for management - can we manage this work in such a way that we can make it more predictable? Give more certainty of hours to staff? That will make an obviously huge impact on people who have got family responsibilities. (Kathy Drysdale)
\end{abstract}

Many women, especially at Sergeant level, feel that combining bringing up children with work commitment is simply too hard.

That's the fear, that if I have children I will lose everything I've worked for over the last fourteen years.
From watching other women working and have kids, it never seems to work out. It's just too damn hard, particularly when you are a high achiever, driving yourself too hard to the point where you just bust.

Another belief strongly held by many officers, particularly men but also many women, is that family friendly policies are to be seen as equally applicable to men as women. Some consider this is insufficiently the case at present.

\section{It just seems to be different rules for women and men in the police unfortunately. It's not a fair balance at all on maternity/paternity leave. (Male Detective/Constable)}

This attitude is a good sign if it means that men are becoming willing to take an equal share of child care responsibility. However, this is not the current reality. Further, some women Detective/Constables believe that more latitude and credit is given to men who do take a share.

\section{I don't ever see a case of a male CIB mem- ber whose wife is at home with a sick child having any problems taking the morning off to run to the doctor or having a day off be- cause they have a baby sick, but when it comes to a female in the CIB actually hav- ing a baby there seems to be like this huge thing.}

Many managers observed that where FEO had been implemented, it was generally working well. Supervisors praised the efforts of those so employed, believing that they get far better value from them because of their need to be better organised and their putting in significantly more effort in the time they are at work.

The gender barriers discussed above are real. However, some, mainly male, officers deny their existence through attributing them to perceptions rather than reality. Similarly, there is debate over what counts as a gender issue particularly with respect to family matters. Indirect gender discrimination occurs when policies or practices differentially and adversely affect women. Since on average women still have greater family responsibilities than men, family issues are still, perhaps regrettably, gender issues. For example, if restructuring and tight resources has made staffing flexibility and use of fractional appointments more difficult (as some managers think), then part time and FEO positions may be squeezed in a manner indirectly discriminatory against those likely to take it, more frequently women as family primary carers.

Lack of space precludes adequate attention to issues facing ethnic minorities in Defence and Police, although my study has some material on this from a focus group of Maori/Pacific Island women officers. A lack of appreciation of cultural differences and reactions to tragedy was noted, and it was felt that there were insufficient numbers 
for the demands and for mutual support. In addition, the experience of seeing and stereotyping Maori and Pacific Islanders in the role of suspects may influence some Pakeha staff to handle the issue of these ethnic groups within the police by constructing their fellow officers as quite different from those they meet in the streets. Some resentment of supposed special treatment in recruitment of Maori and Pacific Island officers was voiced by a few male staff. The focus group resisted strongly reason any feeling that they had had special treatment, and voiced many similar experiences to other women - occurring both as a result of their gender and ethnicity.

The barriers to gender equity discussed in this paper are, as mentioned earlier, not unique to New Zealand. While this is no cause for complacency, this country may in fact be doing better than many overseas, as illustrated for Great Britain by the "painfully slow" progress towards equal opportunities, with police officers "extremely resistant to measures to achieve radical change" and "resistance to allowing women to be employed on the same terms as men deeply rooted in the structure and culture of the force" (Gregory and Lees, 1999: 25: see also Boni, 1998 and Brown and Heidensohn, 1999).

\section{Prospects for Change}

As mentioned earlier, a few women officers consider that gender barriers have now almost disappeared. However, most felt that to be over optimistic. Many incidents related are recent, the family issues are certainly all current, and the financial pressures, the lack of slack and flexibility, and the competitive individualistic environment of today may be leading to further barriers.

Some trends in the Police may make it increasingly crucial for efficiency reasons to ensure that it conserves zealously its human capital, including women. Recruitment and retention in some regions is at critical levels, particularly in CIB. While most CIB officers in my study were enthusiastic about the nature and challenge of their work, there was a high degree of disillusionment on a number of fronts, including levels and structures of remuneration and conditions, incentives for promotion, perceived lack of appreciation of a job well done, inadequate time to study, provision of training, problems over performance of management, adequacy of available resources, and implications of the recent review.

Social and organisational changes may reduce some of the distinctive aspects of police service, with more of the training being university based, and qualifications and skills giving greater mobility. Gregory and Lees (1999) argue that in Britain there has been a "major transformation in the common sense understanding of the police officer's role" (p 29), with community policing among developments which lead to an emphasis on police 'services' rather than a police force. A shift towards managerialism and an output based focus may reduce the strength of the command structure and make the force more like other public sector organisations. Some of these trends might attract more women to policing. The Defence Forces may also become more attractive to women if the balance of its roles moves towards peacekeeping operations.

With regard to the commitment for change within the Police, Commissioner Rob Robinson recently expressed the desire to see more women at the top of the force, saying that many women officers have 'saved him from himself and his testosterone'. Giving evidence to the Law and Order Parliamentary Select Committee, where it had been pointed out that there were no women in the top 27 police positions, Mr Robinson said, perhaps ironically, that it was a problem the police had to be 'very aggressive' in dealing with.

However, there are no magic wands to change the situation overnight. Patient and ongoing work throughout the organisation is needed to develop and implement policies and change behaviours - and eventually attitudes. The recommendations of my study are lengthy, and need to involve officers throughout the Police (Hyman, 2000). Commissioner Robinson's Foreward suggested that the report would act as a springboard for change.

Similarly, Clare Burton showed that there is a long way to go in the Armed Forces. The leadership of the New Zealand Defence Force fully accepted the report and its 121 recommendations. The Human Rights Commission, joint sponsor of the study, referred to it as a blueprint for employers to address gender equity within male-dominated work forces.

So far, this paper has simply assumed that gender equity/ integration in Defence and Police is an unproblematic aim. For many feminists, as well as, for very different reasons, some male army/police personnel and their supporters, this is far from an accurate representation, especially with respect to defence. Even in the case of police, the role of 'keeping order' at demonstrations against government policy, for example, may alienate many feminists, as well as other women and men in agreement with the aims of such demonstrations. The 1981 South Africa Rugby Tour is an obvious example of polarised opinions where such dilemmas arise.

For space reasons, feminist debates on equality in armed forces can only be touched on. The Armed Forces in most of the first world provide opportunities for improved self esteem, employment, education, training, and in particular learning a trade for disadvantaged ethnic minorities and lower socio economic groups, who are invariably overrepresented in the defence workforce. The simple push for gender, race, and class equity hence argues for full integration and equal opportunity. However, feminist antimilitarism, opposed to warfare, unthinking obedience to perhaps intolerable orders, and rape/abuse/prostitution of women which appears invariably to accompany not only war but also overseas bases, understandably considers this view blinkered. 


\section{Future Research}

It will clearly be important to follow up the impacts of the reports discussed in this paper. First, will the Police and Defence Forces match their commitment to gender equity and integration with real change, including the implementation of the bulk of the recommendations? Second, to what extent are the desired results of higher representation of women throughout the workforces, including at top levels, achieved?

Another useful direction would be to undertake similar quantitative, qualitative and case study research in other male dominated workplaces, such as the Fire Service and various blue collar trades.

\section{References}

Boni, N. (1998) Deployment of Women in Policing. London: National Police Research Unit.

Brown, J. and Heidensohn, F. (1999) Contrasts in Policing: lessons from International Comparisons. Paper to Second Australasian Conference on Women and Policing.

Burton, C. (1998) Report of the Gender Integration Audit of the New Zealand Defence Force. Wellington: New Zealand Defence Force and New Zealand Human Rights Commission.

Halford, S. Savage, M. and Wilz, A. (1997) Gender, Careers and Organisations - Current Developments in Banking, Nursing and Local Government. Basingstoke: MacMillan.

Hyman, P. (2000) Opportunities for and Barriers to the Recruitment, Progress, and Retention of Women in the Criminal Investigation Branch (CIB), Wellington: New Zealand Police - available at http:// www.police.govt.nz/download/women-in-cib.pdf

Gregory, J. and Lees, S. (1999) Policing Sexual Assault. London: Routledge

\section{Author}

Prue Hyman

Associate Professor

Women's Studies

Victoria University of Wellington

PO Box 600

Wellington

Prue.Hyman@vuw.ac.nz 